\title{
O allemanismo em Recife e a primeira recepcão de Nietzsche no Brasil
}

\author{
Tiago Lemes Pantuzzi*
}

\begin{abstract}
Resumo: Este artigo tem por objetivo investigar a primeira recepção da filosofia de Nietzsche no Brasil, que ocorre na Escola de Recife. Para tanto, num primeiro momento, examina de forma histórico-filosófica a formação do movimento intelectual dentro da faculdade pernambucana que, entre seus objetivos, busca construir uma identidade nacional que se distancie do predomínio europeu. Em seguida, analisa a primeira citação explícita de Tobias Barreto de 1876 que acontece em meio a esse momento de efervescência sociocultural e serve de mote para os alunos vindouros, concebendo uma filosofia mais combativa e criativa. Por fim, investiga membros estudiosos germanistas que, além de trazerem obras alemãs para a faculdade pernambucana, acreditaram que elas poderiam fornecer o aperfeiçoamento cultural para o Brasil através do allemanismo. Palavras-chave: Nietzsche, recepção, Escola de Recife, Tobias Barreto, allemanismo, Brasil.
\end{abstract}

\footnotetext{
* Doutorando da Universidade Federal de São Paulo, UNIFESP, Guarulhos, SP, Brasil. ORCID https://orcid.org/0000-0003-3962-1149

Correio eletrônico: pantuzzi@gmail.com
} 
Ainda são escassos os trabalhos sobre a recepção do pensamento de Nietzsche no Brasil. Para tal tarefa, é muito importante conhecer o solo em que apareceram os primeiros sinais de apropriação e observar como os escritos foram dispostos e apreciados para termos uma ideia do rumo de suas repercussões. Em vista da falta de trabalhos filosóficos acerca da recepção, vale destacar o ensaio de Scarlett Marton, que analisa justamente esse tema e assevera sua importância ao apontar a necessidade de trabalhos que explorem a recepção de ideias filosóficas na cena brasileira. Segundo Marton, a orientação da formação acadêmica e os seus métodos, programas de ensino e grades curriculares não propiciam a investigação sobre o percurso intelectual dos autores com os quais os estudantes têm contato. Ainda não se sabe como inúmeras ideias filosóficas chegaram ao Brasil, mesmo que essas ideias tenham impactado na cultura, na sociedade ou na política ${ }^{1}$. $O$ preenchimento das lacunas que existem entre os leitores e as obras poderá contemplar questões acerca da formação do pensamento brasileiro. Este trabalho se coloca, mesmo que pontualmente, nessa direção.

Como ponto de partida, tomemos a Faculdade de Direito de Pernambuco, local da mais antiga citação explícita ao nome do filósofo alemão, feita por Tobias Barreto em 1876. A fundação da instituição aconteceu durante o reinado de Dom Pedro I, momento em que surgiram as primeiras faculdades de Direito no Brasil. Na iniciativa, inaugurada por Carta de Lei da Assembleia Geral em 11 de agosto de $1827^{2}$, os lugares escolhidos para abrigar os centros de estudos jurídicos foram Olinda e São Paulo. Não havia outro estabelecimento de ensino superior no Nordeste, por isso o centro pernambucano era tão atrativo para as outras províncias, tornando-se um dos polos de movimentos intelectuais da época ${ }^{3}$. Dentre os inúmeros doutos, os

1 Cf. Scarlett Marton, 2001. p. 253.

2 Cf. Antonio Paim, 1981.

3 “A Faculdade de Direito da capital pernambucana, por ser à época o único estabelecimento de ensino superior no Nordeste, recebia alunos das diversas províncias daquela região. Essa circunstância 
maiores representantes são Tobias Barreto, Sílvio Romero, Clóvis Bevilacqua e Euclides da Cunha, todos participantes da conhecida "Geração de 1871". A compreensão do que se encontra acerca do pensamento nietzschiano nas citações dos alunos de Recife, do fundador Tobias Barreto e das gerações vindouras, está conectada com a motivação intelectual que surgia naquele momento e que dá origem à Escola de Recife, palco de grandes debates políticos em que se discutiam o poder e a autonomia das províncias ${ }^{4}$.

Em 1848, irrompe em Pernambuco a Revolução Praieira, que influenciará fortemente o sergipano Tobias Barreto, pois trará diversas obras a partir das quais ele fará oposição em defesa do germanismo. Embora a Praieira estivesse em um terreno ocupado por ideias socialistas, não o foi em sentido lato, pois aconteceu devido ao fracasso do controle da província por parte dos conservadores. A luta durou até 1850 e resultou na abolição do Poder Moderador, expulsão dos portugueses e na nacionalização do comércio e varejo. Em vista das análises precedentes e do impacto histórico de tais episódios, pode-se afirmar que a Praieira foi a última revolução provincial e marcou o fim do ciclo revolucionário de Pernambuco. Entre as novidades que aparecem nesse momento estão as obras francesas que chegaram a Recife dando força ao "maligno vapor pernambucano"5 com ideias de crítica social e socialismo ${ }^{6}$. Essa ebulição é causada pelas discussões acaloradas dos alunos, com a chegada de novos livros, ideias e pensadores que expandem seus

permitiu a irradiação das ideias da Escola do Recife, formando-se alguns núcleos de seus partidários no Ceará, em Sergipe e na Bahia". (Antonio Paim, 1981.p. 69.)

4 "Naqueles anos, esteve em jogo a unidade territorial do Brasil, e o centro do debate político foi dominado pelos temas da centralização ou descentralização do poder, do grau de autonomia das províncias e da organização das Forças Armadas.” (Boris Fausto, 2013. p. 139.)

5 "É importante lembrar que 1848 não foi um ano qualquer, pois nele uma série de revoluções democráticas varreu a Europa. Em Olinda e Recife, respirava-se o que um autor anônimo, adversário das revoluções, chamara muitos anos antes de 'maligno vapor pernambucano'. $O$ vapor se compunha agora também da crítica social e ideias socialistas”. (Boris fausto, 2013. p. 152.)

6 Cf. Boris Fausto, 2013. p. 154.

162 | Cad. Nietzsche, Guarulhos/Porto Seguro, v.40, n.1, p. 160-192, janeiro/abril, 2019. 
horizontes. $\mathrm{O}$ historiador Boris Fausto aponta que ideias socialistas foram veiculadas em Recife, a pedido do presidente da província, para embelezá-la. "Não era o socialismo de Marx, pouco conhecido naquela altura, mesmo na Europa, mas o de autores franceses como Proudhon, Fourier e o inglês Owen"7. Por isso Sergipe e Pernambuco eram considerados centros de obscurantismo, pois eles se opunham à essa tradição de pensadores franceses recomendados pelo governo e essa entrada de teóricos socialistas significava esse embelezamento, uma tentativa artificial de sofisticação. A motivação e a insistência da Escola de Recife em persistir num estudo enraizado na cultura alemã é algo que vai além do projeto da província. Tobias Barreto é o regente dos debates, intensificando os ânimos contra os programas oficiais e criticando de forma agressiva os pilares doutrinários da Academia e do Direito, que tinham como base um positivismo religioso ${ }^{\mathbf{8}}$.

Dos diversos seguidores de Tobias Barreto, poucos certamente atuaram em condições tão desfavoráveis como esse núcleo sergipano. Província pequena e pobre, sem ter produzido nunca mercadoria importante de exportação que lhe desse o mínimo de florescimento econômico, Sergipe seria à época um centro de obscurantismo, abrir ali caminho para ideias em desacordo com a tradição, representava uma empreitada que se revestia de lances de verdadeiro heroísmo?.

Além da revolução, a Guerra do Paraguai ou Guerra da Tríplice Aliança também teve grande influência na vida do professor sergipano. Ela durou de 1864 a 1870 e é tida como o acontecimento internacional que marca o período do Segundo Império. Junto com o desempenho

\footnotetext{
7 Boris Fausto, 2013. p. 152.

8 "Deve-se acentuar que a presença de Tobias Barreto na Faculdade de Direito contribuía para exacerbar os ânimos e dar ao debate das ideias aquela agressividade tão peculiar à personalidade do pensador sergipano. A existência entre os professores de três mestres que defendiam opiniões de todo em desacordo com o teor e o espírito dos programas dos estabelecimentos oficiais de ensino não significa que na velha Academia não mais predominasse aquele corpo de doutrinas que tinham por pilastra a atribuição de uma origem divina para o direito." (Antonio Paim, 1981. p 54.)

9 Antonio Paim, 1981. p 70.
} 
em uma campanha política renovadora pós-guerra, Barreto rompe com a filosofia oficial do Império e se liberta da mentalidade brasileira comprometida com a teologia e o conservadorismo, alforriando-se do tradicionalismo. Esse rompimento "não representa fenômeno isolado, mas eco do novo estado de espírito pelo qual vão se deixando empolgar aquelas camadas politicamente ativas e verdadeiramente representativas da jovem Nação"10. Sem dúvida, o surto de ideias novas fomenta a busca de Barreto por novos materiais; momento em que se encaixa a viabilidade de acesso aos textos alemães. $\mathrm{O}$ diplomata maranhense Graça Aranha, aluno da faculdade pernambucana, aponta a importância do professor para a instituição em um depoimento que mostra traços do início do movimento intelectual em Recife.

O que ele dizia era novo, profundo, sugestivo. Abria uma nova época na inteligência brasileira e nós recolhíamos a nova semente, sem saber como ela frutificaria em nossos espíritos, mas seguros que por ela nos transformávamos. [...] Prosseguíamos impávidos, certos de que, conduzidos por Tobias Barreto, estávamos emancipando a mentalidade brasileira, afundada na teologia, no direito natural, em todos os abismos do conservadorismo ${ }^{11}$.

Na Escola de Recife, as discussões filosóficas ganhavam a mesma importância que os assuntos jurídicos, retirando o Direito de seu altar sagrado. Famosa pelos estudos políticos, o escopo do movimento também caminhava pelo terreno da literatura e da poesia, mas passou a ter a filosofia como elemento unificador, já que os corpos docente e discente sempre incluíam a discussão filosófica nas disciplinas jurídicas. Dentre os inúmeros objetivos da Faculdade estava o desenvolvimento de uma autonomia nacional e a tentativa de construir uma identidade, algo que não se pautasse somente nas

10 Trecho da introdução feita pelos especialistas nos estudos da Escola do Recife e Tobias Barreto, Paulo Mercadante e Antonio Paim, 1977. p. 14.

11 Depoimento de Graça Aranha trazido pelos especialistas nos estudos da Escola do Recife e Tobias Barreto Paulo Mercadante e Antonio Paim in: BARRETO, Tobias. Estudos de filosofia. São Paulo: Grijalbo, 1977. p. 20.

164| Cad. Nietzsche, Guarulhos/Porto Seguro, v.40, n.1, p. 160-192, janeiro/abril, 2019. 
influências europeias. Essa incumbência cultural em Recife era tão importante que o grupo formado por Barreto continuou com essa missão mesmo após sua morte ${ }^{12}$. Antonio Paim, expõe em seu livro sobre a filosofia do Recife que os alunos recifenses conheceram muitos dos autores estrangeiros através da Questão Coimbrã ${ }^{13}$. Comenta também sobre o estímulo que tinham em constituir uma tradição cultural autônoma, na qual os brasileiros tentavam se livrar do peso da herança cultural portuguesa para conquistar um espaço para sua autonomia. A divergência entre os centros de ensino, cada um com sua base em um estilo europeu, causou a rivalidade entre as escolas. Essa condição é comentada por Sílvio Romero ${ }^{14}$; ele escreve que a Escola de Recife trazida por Tobias Barreto era chamada "ridiculamente de escola teuto-sergipana" por escritores fluminenses e jornalistas da corte imperial. Em contrapartida, Barreto apontava seus opositores como membros da "escola gallo-fluminense" na tentativa de debochar daqueles que os ridicularizavam. Essa oposição também é tratada no livro lançado em 1878, A filosofia no Brasil, de Sílvio Romero, em

12 "Assim, em torno a Tobias Barreto, forma-se numeroso grupo de partidários entusiasta das novas doutrinas: Artur Orlando, Clóvis Beviláqua, Martins Júnior, França Pereira, Teotônio Freire, José Freitas, Faelante da Câmara, Graça Aranha, Gumercindo Bessa, Fausto Cardoso e inúmeros outros. A grande maioria fez-se jurista. Outros dedicaram-se principalmente à literatura, como Graça Aranha, França Pereira e Teotônio Freire. Clóvis Beviláqua e Faelante da Câmara, entrando para o corpo docente da Faculdade, depois da morte de Tobias Barreto, em 1891, incumbiram-se de levar suas ideias até as novas gerações, enquanto as condições do País favoreceram essa missão." (Antonio Paim, 1981. p. 56.)

13 "Possivelmente, a fonte imediata para o conhecimento desses autores teria sido a famosa disputa literária ocorrida em Portugal, por volta de 65, e que passaria à História com o nome de Questão Coimbrã. Esse e outros fatos terão contribuído, sem dúvida, para sugerir caminhos na busca de ideias novas em que iria lançar a intelectualidade brasileira, como pretende José Veríssimo. À conta destes, entretanto, é que não se pode explicar o movimento de ideias no Brasil, já que o principal estímulo que o nutria era a própria sociedade brasileira que buscava estabelecer uma tradição cultural autônoma. $O$ peso da herança cultural portuguesa e os próprios vínculos com a antiga metrópole são sem dúvida um dado da questão. Mas esta envolve ainda o estímulo próprio. De todos os modos, as obras de Scherer, Renan, Max Müller e Taine, que já então eram do conhecimento dos alunos da Academia recifense, influíram sobre Tobias Barreto no sentido de levá-lo ao rompimento com o espiritualismo. Contribuíram também para o despertar o seu interesse por esse tema a que dedicou alguns dos artigos de 1870.” (Antonio Paim, 1981. p 12.)

14 Sílvio Romero (1851-1914) foi crítico, ensaísta, folclorista, polemista, professor e historiador da literatura brasileira. Em 1868 se matriculou na Faculdade de Direito de Pernambuco.

Cad. Nietzsche, Guarulhos/Porto Seguro, v.40, n.1, p. 160-192, janeiro/abril, 2019. 
que o autor questiona o meio acadêmico carioca ao mesmo tempo em que tece inúmeros elogios a Tobias Barreto ${ }^{\mathbf{1 5}}$. A concorrência entre as instituições de ensino também vem da formação de uma frente que a Escola de Recife faz contra o positivismo.

Podemos observar essas características da preocupação pelo estabelecimento de uma tradição cultural autônoma em um texto que faz parte da obra completa de Tobias Barreto lançada pelo Governo do Estado de Sergipe em 1923, as Considerações indispensáveis de Sylvio Roméro $^{\mathbf{1 6}}$. A parte introdutória é uma pequena apresentação dos textos selecionados para a publicação das obras completas e também serve para esclarecer alguns pontos que o comentador considera urgentes para novos leitores, elucidando algumas características sobre o escritor, jurista e filósofo sergipano. Esse escrito inserido nas obras completas é importante, pois é de um contemporâneo de Barreto e também uma apologia ao movimento intelectual pernambucano e ao seu fundador, e mostra a motivação da Escola de Recife e a estima que seus membros tinham pela cultura alemã. Pode-se observar um desses momentos de intimidade com a língua tedesca quando Romero afirma que Tobias Barreto foi o inaugurador e criador do "allemanismo" na literatura brasileira. Na introdução ele diz: "Era uma cousa por todos sabida, e geralmente repetida até como uma censura, uma grave critica, que essa corrente havia sido aberta em nossas lettras por Tobias Barreto, secundado n'este ponto pelo signatario destas linhas"17.

Romero mostra admiração e respeito por Tobias Barreto ao tomar a posição de defesa na questão da importância e do papel do autor sergipano que, além de ser o fundador da Escola de Recife,

15 Sílvio Romero pode ser considerado o maior defensor de Tobias Barreto. Em 1909 ele escreve Zeveressimações ineptas da crítica, em que ataca José Veríssimo por não dar a importância merecida a Barreto em sua obra.

16 Esse texto acompanha também a $2^{a}$ edição dos Estudos Alemães publicado por Sílvio Romero em 1892. Embora a edição de 1923 lançada pelo Governo do Estado de Sergipe traga o texto introdutório com o nome do autor Sylvio Roméro, consideramos que isso seja uma característica da grafia da época, pois todos os livros do autor, assim como os livros de seus comentadores, o trazem como Sílvio Romero.

17 Sílvio Romero, 1926, p. XV.

166 | Cad. Nietzsche, Guarulhos/Porto Seguro, v.40, n.1, p. 160-192, janeiro/abril, 2019. 
é também o precursor do germanismo brasileiro. $\mathrm{O}$ historiador da literatura brasileira aponta que ele iniciou três evoluções na vida intelectual do país e para todas elas apareceu um usurpador reivindicando os títulos da precedência. Nesse sentido, o primeiro movimento foi o do germanismo, que Tobias Barreto trouxe para as terras brasileiras, mas que foi dito por alguns jornalistas do período que teria sido trazido pelo escritor alemão Carlos de Koseritz. Romero também traz o poeta baiano Castro Alves ${ }^{18}$, que foi tido por seus bajuladores como o responsável pela reação condoreira contra o subjetivismo do romantismo poético ${ }^{19}$. E por fim, na reação do naturalismo darwiniano no direito, apareceu José Hygino Duarte Pereira que publicou artigos forjados a partir do arranjo de textos já escritos por Barreto e publicados na obra Estudos de Direito ${ }^{\mathbf{2 0}}$.

Barreto é figura popular tanto na faculdade quanto na cidade pelas suas disputas poéticas com Castro Alves e pelas fortes críticas que tecia ao cristianismo. Suas convicções acerca dos assuntos religiosos o colocavam constantemente em debates polêmicos com os católicos. "Advogava Tobias Barreto o mais absoluto respeito aos sentimentos religiosos, tendo manifestado sempre a preocupação de circunscrever ao terreno filosófico as suas divergências com os católicos $^{21} "$. O período em que o sergipano passa no município

18 "Chegando ao Recife, Tobias Barreto afirma sua condição de poeta, dedicando à cidade, que ele chama de "cabocla civilizada", o poema "À Vista do Recife", entrada triunfal para o condoreirismo que iria marcar sua trajetória poética de romântico da quarta geração. É o poeta que domina os primeiros anos de Tobias no Recife. Poeta inflamado, conclamando o povo para a luta, tendo como mote a guerra do Paraguai. É ele que devolve aos pernambucanos a capacidade de crer, novamente, no futuro, depois das derrotas de 1817, 1824, 1842 e 1848. Nas poesias do sergipano flui a convocação patriótica, que recebe do povo mais que aplauso nas ruas, nos teatros, pelos locais públicos, a consagração literária, afirmando um talento que rivaliza com Castro Alves, poeta da Bahia." (Luiz Antonio Barreto, 1990. p. 12.)

19 O condoreirismo faz parte da terceira fase da poesia romântica no Brasil e tem o aspecto social como principal característica. As poesias tinham como tema o abolicionismo e a república. Castro Alves, autor criticado por Sílvio Romero no texto, ficou conhecido como o poeta dos escravos pelo seu poema Navio negreiro.

20 Cf. Ś́lvio Romero, 1926.

21 Antonio Paim, 1981.p 13.

Cad. Nietzsche, Guarulhos/Porto Seguro, v.40, n.1, p. 160-192, janeiro/abril, 2019. | 167 
de Escada, em Pernambuco, é decisivo para o rumo de sua vida intelectual, pois é onde ele estabelece sua relação com a cultura alemã e disso decorre seu rompimento com o positivismo. Ruptura que se dá porque o fundador da Escola de Recife acredita que os partidários de Comte não poderiam satisfazer as solicitações da intelectualidade. O positivismo não podia responder a todas as questões de Tobias Barreto, pois, dentre seus problemas, estava a indagação da essência e dos limites da filosofia, e para isso seria necessário a metafísica ${ }^{22}$.

O próprio Tobias Barreto relata que, por ocasião da defesa da tese por Ślvio Romero, na Faculdade de Direito do Recife, quando este declara que a metafísica estava morta, “já eu nutria minhas dúvidas a respeito da defunta, que o positivismo tinha dado realmente por morta, porém que ainda sentia-se palpitar". [...] Temos assim que a rejeição do positivismo foi o resultado da busca por uma solução da questão que se propunha a si mesmo já nos primórdios do seu contato com a doutrina de Augusto Comte, isto é, a determinação dos limites em que se poderia aceitar a metafísica, entendida esta como a discussão de problemas propriamente filosóficos. Este o objetivo a que se propôs Tobias Barreto, segundo se pode deduzir das restrições opostas ao positivismo no estudo "A religião Natural de Jules Simon", escrito em 1869, antes comentado ${ }^{23}$.

Sílvio Romero escreve que desde o começo do século XIX, os brasileiros têm tido contato com alemães que puderam despertar o gosto pelas ideias e pela cultura alemã, mas assevera que nenhum deles foi, em qualquer grão, propagandista da necessidade do abandono da intuição francesa e da passagem para a intuição germânica, como um reforço do pensamento brasileiro ${ }^{24}$. Dessa forma a influência sofrida por Tobias Barreto provinha de uma única fonte, a "Alemanha, [que] não pode ser compreendida como a de um único sistema, pronto e

22 Cf. Antonio Paim, 1981. p 16.

23 Antonio Paim, 1981. p 41.

24. Sílvio Romero, 1926.

168 | Cad. Nietzsche, Guarulhos/Porto Seguro, v.40, n.1, p. 160-192, janeiro/abril, 2019. 
acabado. Atuava, por outro lado, como estímulo às suas pesquisas filosóficas, o ambiente nacional e a luta em que se engajara contra o tomismo e o positivismo"25. Romero afirma que a relação de Barreto com os textos estrangeiros não vem de traduções, mas do original; ele aprende alemão comprando um dicionário e um livro de gramática em um livreiro de Recife. "Tobias apaixonou-se pela língua, pelos autores, pelas idéas, por tudo quanto vinha da Allemanha, e não abandonou mais até morrer o seu querido allemanismo"26. Paim também escreve sobre essa desenvoltura que o pensador brasileiro tinha com as línguas.

Não sabemos ao certo quando conseguiu ler com desembaraço nessa língua. Segundo sua própria indicação, no último ano da Faculdade (1869) fizera uma tentativa de aprendê-la. O certo, entretanto, é que já nos primeiros escritos de Escada (1871/72), aparecem referências a trabalhos de filósofos alemães seus contemporâneos. Quanto a Haeckel, é possível que só viesse a conhecê-lo mais tarde. Num artigo de 1875, menciona a História Natural da Criação, de Haeckel (publicada, na Alemanha, em 1868), e o considera, juntamente com Edward von Hartmann, "homens de reputação feita, reconhecidamente sábios"27.

O primeiro artigo filosófico escrito por Tobias Barreto foi sobre Guizot e a escola espiritualista do século XIX, publicado em 1868. $O$ professor de Recife refuta a tese de Guizot que considera a escola de Cousin tímida e orgulhosa por não aceitar os dados da revelação cristã. Segundo Paim, o artigo filosófico de Barreto já mostra certo lampejo do espírito de rebeldia do autor por se opor à filosofia oficial do Segundo Reinado, diferenciando o ecletismo de Cousin e as tentativas de restauração escolástica contra o sensualismo ${ }^{28}$. A doutrina de

25 Antonio Paim, 1981. p 44

26 Sílvio Romero, 1926, p XX.

27 Antonio Paim, 1981. p 41.

28 Cf. Antonio Paim, 1981. p. 5.

Cad. Nietzsche, Guarulhos/Porto Seguro, v.40, n.1, p. 160-192, janeiro/abril, 2019. 
Victor Cousin ${ }^{29}$ era ensinada nos cursos preparatórios da Faculdade de Direito em Recife e em São Paulo, assim como na Faculdade de Medicina no Rio de Janeiro e Salvador. "É compreensível, pois, que Tobias Barreto tivesse acesso à meditação filosófica pela mão dos partidários brasileiros de Cousin"30. Mas em 1869, no último ano da faculdade, Barreto publica alguns textos que assinalam seu rompimento com o ecletismo.

Tamanha era a admiração de Romero pelos textos alemães que ele escreve que a leitura de franceses em Recife entre 1868 e 1870 fez com que seu apreço pela cultura germânica só crescesse. Também ajudou a propagar o "allemanismo" no espírito popular brasileiro, sobretudo com a utilização da crítica alemã, pois através dela a Escola do Recife revigoraria a identidade nacional. Porém seu entusiasmo foi ainda mais longe que o de Tobias Barreto, já que para ele, antes das nações atenderem aos seus instintos particulares, elas deviam se voltar para o progresso da civilização, lutando por ele. Nesse sentido, o Brasil deveria se corrigir e ter a Alemanha como exemplo a ser seguido. No entender do autor, não é um bom exemplo uma nação seguir outra, mas deve-se compreender a relação com os grandes povos, com aqueles que representam um papel original na história.

O ideal, porém, da Allemanha como exemplo a seguir tem tudo de nobilitante, d'ella é que podem vir melhores ideias que o reanimem, sem tirar-lhe a consciencia de seu proprio ser. A corrente francesa tem suffocado, pela imitação, a individualidade d'este povo: o germanismo, que fornece ideias em vez de phrases, vivificará a personalidade perdida por meio da crítica de nós mesmos ${ }^{31}$.

29 Victor Cousin atuou em várias áreas, ficou famoso como líder da escola eclética e fez parte da Academia Francesa de Letras. Atuou em filosofia, política, história e educação francesa. Também conhecido por editar a obra de Descartes e traduzir Platão.

30 Trecho da introdução feita pelos especialistas nos estudos da Escola do Recife e Tobias Barreto Paulo Mercadante e Antonio Paim, 1977. p. 14.

31 Sylvio Roméro, 1926, p. XXI

$170 \mid$ Cad. Nietzsche, Guarulhos/Porto Seguro, v.40, n.1, p. 160-192, janeiro/abril, 2019. 
Uma escola severa é necessária para os países que não conseguem se corrigir. Por trás dessa correção do povo brasileiro se encontra a necessidade que Romero vê de ordenar, melhorar, pôr em bom estado, arrumar, reparar ou remediar a população, como se ela mesma não pudesse resolver seus próprios problemas e precisasse de uma configuração "elevada" vinda de fora para se tornar um grande povo, o povo ideal. Afirma também que no Brasil há um povo que não tem vida própria, que não passam de intérpretes de vulgaridades lusas e francesas ${ }^{32}$. Essa afirmação parece mostrar preconceito com a população brasileira, mas o professor Marcelo Chiaretto aponta em seu artigo, "O nativismo crítico e germanista de Sílvio Romero" "33, que o autor procura o Volksgeist, o espírito nacional do povo. As críticas são feitas tendo como base a preocupação com o desenvolvimento de um espírito nacional, algo que desempenhasse um papel ativo na formação da consciência do país, mesmo que fosse à custa de choques violentos e radicais. Embora possa soar como algo hostil, a meta seria o estabelecimento de uma nação culta, livre e original. Romero afirma que no domínio das ideias há duas grandes manifestações, a ciência e a literatura. "Quanto á primeira, Tobias é muito illustrado para pretender que ella seja um patrimonio da Allemanha, como uma intelligencia má do seu pensamento tem podido sugerir"34. Para o escritor crítico do Brasil, a ciência contemporânea tem sua sede principal na Alemanha, mas é um produto da civilização ocidental. Quanto à literatura, a qualidade poética de Barreto o fazia perceber que ela não era um patrimônio alemão, mas mesmo assim considerava de grande importância que a disciplina do pensamento e a severidade alemã fizessem parte da formação brasileira.

32 Antonio Candido, 1978. p. 3-5

33 Cf. Marcelo Chiaretto, 2012.

34 Sylvio Roméro, 1926, p. XXI

Cad. Nietzsche, Guarulhos/Porto Seguro, v.40, n.1, p. 160-192, janeiro/abril, 2019. | 171 
Quanto á litteratura, elle é muito bom poeta para pretender que o cunho da nacionalidade possa della no todo ausentar-se. Quer em um ou outro ramo, teve sem dúvida em vista a disciplina do pensamento, a severidade da investigação, juntas constituem o sello da inteligencia tedesca. Quer que contrahamos tão salutares hábitos no estudo severo da sciencia e da litteratura germânicas, incontestavelmente as mais fecundas da actualidade ${ }^{\mathbf{3 5}}$.

Essa fase descrita por Romero é conhecida como o terceiro momento da história da escola. Segundo Paim, a Escola de Recife passou por quatro fases. A primeira vai da década de 1860 até 1875 e se caracterizava pelos formadores como simples participantes do movimento que buscava alcançar a renovação no campo das ideias. A segunda fase é marcada pela morte da metafísica trazida por Romero e as meditações sobre o problema trazidas por Barreto. $\mathrm{O}$ livro A Filosofia no Brasil marca a transição e o rompimento com o positivismo. A terceira fase se dá na década de 1880 e corresponde ao apogeu, com a corrente da Escola de Recife enfrentando o positivismo e o espiritualismo, além da publicação dos estudos de Barreto e de vários membros da Escola. A última fase é a do declínio, em que há o abandono da atividade filosófica e o fim da publicação sistemática de obras e estudos, época também marcada pela morte de Fausto Cardoso em 1906. Mesmo após a morte de Tobias Barreto, os estudos ganharam continuidade, mas passaram a trilhar novos caminhos.

Em seguida à morte de Tobias Barreto (1889), dá-se conta de que o entendimento da filosofia como epistemologia era incompatível com a ideia positivista de que a filosofia seria uma síntese de ciências particulares. Procurou mesmo desenvolver a temática de uma teoria do conhecimento. Manteve-se, por isto mesmo, equidistante da polêmica travada entre seguidores da Escola do Recife a propósito de "monismo mecanicista" e "monismo teleológico". Contudo, não teve forças para encaminhar a Escola do Recife nesse novo rumo e acabou enveredando por outros caminhos ${ }^{36}$.

35 Sylvio Roméro, 1926, p. XXII.

36 Antonio Paim, 1981. p 64.

172 | Cad. Nietzsche, Guarulhos/Porto Seguro, v.40, n.1, p. 160-192, janeiro/abril, 2019. 
Mesmo com o ambiente desfavorável, o pequeno grupo de pensadores preservava a obra e o pensamento de Tobias Barreto para que fosse passado para as novas gerações. Artur Orlando da Silva, jornalista, jurista, ensaísta e aluno da Escola de Recife acredita que o legado de Tobias Barreto foi o de tornar possível uma legítima filosofia brasileira ${ }^{37}$.

O registro mais antigo da obra de Nietzsche no Brasil está na publicação do artigo, datado de Escada, em 26 de março de 1876 publicado na Província do Recife por Tobias Barreto. O professor sergipano publicou vários trabalhos sobre escritores da Alemanha nos jornais dos quais fez parte, sendo inclusive editor e redator de um jornal em alemão que circulava no norte do Brasil em 1875, o Campeão Alemão $o^{38}$. Era através de sua revista que ele ampliava os contatos intelectuais com figuras brasileiras e alemãs ${ }^{39}$. $\mathrm{O}$ folclore popular diz que o germanista brasileiro enviava cópias de seu jornal produzido em Pernambuco e recebia alguns textos europeus que circulavam na época, sendo essa provavelmente uma das maneiras pelas quais conseguiu o texto de Nietzsche. A primeira citação explícita do filósofo alemão é direcionada ao Sr. Rodrigues, em resposta às críticas da revista Novo Mundo ao livro Ensaios e Estudos de Filosofia e Crítica de Tobias Barreto: "Assim Guizot achou quem dissesse que ele não sabia escrever bem o francês. Strauss, o sábio, o venerado Strauss, encontrou também o Sr. Nietzsche da Basiléia que quis provar-lhe a sua ignorância da língua alemã!"’0. Vale

37 "A Escola do Recife prosperou com Tobias e com seus seguidores, jovens ardentes de liberdade, propagandista da abolição da escravatura, da proclamação da república, democratas e socialistas, que voltavam aos seus Estados e se alistavam nas justas causas da liberdade, reagindo às múltiplas formas de dominação senhorial" (Luiz Antonio Barreto, 1990. p. 13).

38 Cf. Bernadette Siqueira Abrão (org.), História da filosofia: Col. "Os Pensadores", São Paulo: Editora Nova Cultural, 2004. p. 466.

39 Cf. Tobias Barreto, 1991. p. 223. O capítulo de correspondências traz nomes como Carvalho Lima Júnior, Sílvio Romero, Arthur Rolando, Paulo Apfelsdtedt, Richard Lesser, Henry Lange, Fritz Muller, entre outros.

40 Tobias Barreto, 1991. p. 152. 
lembrar que o texto nietzschiano a que Barreto se refere é a Primeira consideração extemporânea, escrito em 1873. Ou seja, o fundador do movimento intelectual de Recife já tinha conhecimento desse texto, publicado na Alemanha havia apenas três anos, mostrando a proximidade e o avanço do grupo de estudos germânicos de Recife. Paim também observa essa proximidade excepcional que Tobias Barreto tinha com os círculos intelectuais alemães, além de ler os textos na língua original e não precisar de traduções francesas que eram base de muitas faculdades da época.

\begin{abstract}
Deve-se destacar que Tobias Barreto estava bem relacionado com os círculos intelectuais da Alemanha e acompanhava com regularidade e sem grande atraso as publicações que ali se faziam. Basta mencionar que, por volta de 1885, cita num de seus escritos a edição alemã de 1883, de O Capital, de Carlos Marx. Conheciam-no e fizeram referências elogiosas à sua obra, entre outros, Ernesto Haeckel e Alberto Lange. Sílvio Romero faz notar que, em 1874, quando Tobias Barreto iniciou um artigo sobre a obra de Eduardo von Hartmann, não havia tradução francesa da Filosofia do Inconsciente, nem da obra de Schopenhauer, mencionada no texto com o intuito de ressaltar o conhecimento adquirido por Tobias da língua e do movimento intelectual alemão do período mencionado ${ }^{41}$.
\end{abstract}

No texto em que o Sr. Nietzsche é apresentado, Tobias Barreto está respondendo à crítica de um redator que o acusa de antipatriotismo e ataques a Deus, entre outras coisas. Ele aponta o contrassenso do Sr. Rodrigues nas acusações e apontamentos ao seu trabalho, sem ao menos ter lido nada daquilo que criticou, pois as críticas não possuiriam fundamento e nem sentido histórico, as informações seriam jogadas aleatoriamente e teriam como públicoalvo pessoas que nunca ouviram falar em nenhuma das obras ou dos nomes ali citados. É nesse momento que ele menciona alguns nomes que sofreram críticas ao seu modo de escrever e traz Strauss e o Sr. Nietzsche ao texto. Chama a atenção que Barreto toma uma posição

41 Antonio Paim, 1981. p 43.

174| Cad. Nietzsche, Guarulhos/Porto Seguro, v.40, n.1, p. 160-192, janeiro/abril, 2019. 
parecida com a do Sr. da Basileia, já que na Primeira consideração extemporânea o filósofo alemão aponta a falta de preparo filosófico e a argumentação problemática cheia de falhas de Strauss, o mesmo que o fundador da Escola de Recife faz em resposta ao redator no artigo publicado em sua revista. Vemos que o primeiro contato do germanista brasileiro se dá em um terreno estilístico em que é analisada e comentada a forma da escrita e o domínio da língua alemã. Tobias Barreto se refere ao filósofo alemão como o "Sr. Nietzsche da Basiléia", o que mostra a percepção de tê-lo como um de seus contemporâneos, referindo-se a ele como "senhor", do mesmo modo que utiliza para fazer menção a outros professores e amigos, como o Sr. José Oiticica ou Sr. Rodrigues, por exemplo. Kant, Spinoza ou Schopenhauer não são citados como Sr. Kant, Sr. Spinoza ou Sr. Schopenhauer. A maneira como se refere a Nietzsche chamando-o de senhor é muito interessante porque é um hábito francês de se dirigir aos que estão vivos, costume este também incorporado na maneira de agir dos brasileiros durante $o$ Segundo Reinado, quando a cultura francesa começa a predominar sobre os antigos costumes lusitanos. Nos tempos atuais ainda se referem aos filósofos como senhores na França. A primeira consideração extemporânea publicada em 1873 é assinada da seguinte forma na capa da primeira edição da publicação original "Dr. Friedrich Nietzsche, ordentl, Professor der classischen Philologie an der Universität Basel", o que explica por que o professor de Recife se refere ao filósofo como Nietzsche da Basiléia. De 1873 a 1876 quase não encontramos repercussão da extemporânea nietzschiana na Alemanha e muito menos no Brasil, o que nos leva a crer que Tobias Barreto teve acesso ao texto original. Chama nossa atenção o fato de que a primeira citação de Nietzsche no Brasil coincide com o momento em que Krummel ${ }^{42}$, como está registrado no livro Nietzsche und der Deutsche Geist, encontra poucas citações do filósofo na Alemanha, o que torna a citação brasileira

42 Richard Frank Krummel, 1998. 
um pouco incomum, já que atesta a presença de Nietzsche no Brasil antes de ele se tornar popular entre os alemães. Segundo o estudo de Krummel, de 1867 a 1889, o nome do filósofo alemão foi citado na Europa setenta e nove vezes. A partir da década de 1890, há um salto e o nome passa a cobrir cento e noventa e duas páginas ${ }^{\mathbf{4 3}}$.

Outro dado importante é que o conhecimento de Nietzsche antecede a publicação de Assim falava Zaratustra, asseverando ainda mais o nível de relação que o professor brasileiro tinha com o pensamento alemão. Essa obra nietzschiana é produzida entre 1883 e 1885, quase dez anos depois da citação no Brasil. Isso deve ser destacado, porque a obra citada acima é uma das responsáveis por difundir os textos nietzschianos fora da Europa. A leitura brasileira aponta não só o contato com o material de Nietzsche antes dos estudos rigorosos feitos por Colli e Montinari, mas também para uma leitura quase simultânea com as primeiras que ocorreram na Europa. Vemos no Brasil um contato que se dá ao mesmo tempo em que acontecem as primeiras apropriações alemãs, já que o filósofo de Sils-Maria passa a ser pesquisado de forma intensa somente depois de seu colapso mental de 1890. O conhecimento dos textos de Nietzsche não foi algo isolado, restrito somente à leitura de Barreto, já que teve repercussão entre os estudantes vindouros de Recife. Por exemplo, nota-se o modo como os alunos se relacionam com os textos no depoimento de Gilberto Amado, que estudou na turma de 1905. No trecho citado, o filósofo alemão é tido como ponto de passagem para Goethe, um guia que encaminha os estudantes para a literatura alemã.

Em Pernambuco líamos tudo. Prosseguíamos na reta do darwinismo e do haeckelismo seguindo os autores franceses, ingleses, italianos que entravam em circulação, mas sem tomar a peito o transformismo, sem formar batalhão. Nietzsche nos levara a Goethe ${ }^{\mathbf{4 4}}$.

43 Steven E. Aschheim, 1992. p. 32.

44. Wilson Martins, 1996. p. 250.

$176 \mid$ Cad. Nietzsche, Guarulhos/Porto Seguro, v.40, n.1, p. 160-192, janeiro/abril, 2019. 
Amado escreve que em Pernambuco eles faziam um caminho contrário na linha cronológica dos autores. Nietzsche os levara a Goethe e Goethe os levara a Schopenhauer. Em Tobias Barreto não há registro que explique como ele chegou a determinados autores, como Nietzsche e Schopenhauer, por exemplo. No levantamento feito pela própria Faculdade de Pernambuco, que conservou a biblioteca de Tobias Barreto, não encontramos os livros dos autores que ele cita. Contudo, tomando-se como base o caminho intelectual às avessas que os alunos de Recife faziam e aplicando-o ao fundador da Escola de Recife, pode-se notar algo muito interessante, pois a citação que traz o nome do autor de Assim falava Zaratustra aparece em 1876, e as inúmeras citações sobre Schopenhauer só aparecem depois dessa data. É importante salientar que tanto Schopenhauer quanto Goethe são citados na Primeira consideração extemporânea. Nesse sentido, levando em conta as datas dos documentos e a coleção completa da obra de Tobias Barreto organizada pelo Governo de Pernambuco, pode-se dizer que a curiosidade e os textos de Schopenhauer e Goethe podem ter aparecido na Escola de Recife depois da leitura que fizeram do escrito nietzschiano.

$\mathrm{Na}$ Primeira consideração extemporânea ${ }^{45}$, Nietzsche ataca David Strauss por considerá-lo a negação do espírito alemão que foi trazido por Schopenhauer e Wagner. A crítica é voltada aos eruditos, à falta de estilo e à necessidade de uma autêntica cultura [Kultur] alemã. Nietzsche acusa seus compatriotas de confundirem a superioridade militar com a cultural. Para o filósofo de Sils-Maria, o otimismo de

45 Segundo Denat, os trabalhos conhecidos como extemporâneos foram tecidos para pôr um fim no mal-entendido que apareceu na primeira obra de Nietzsche, que a princípio foi tomado somente como um elogio a Wagner ou como um exercício filológico. As Considerações extemporâneas buscam questionar a cultura, e o termo "extemporâneo" é utilizado porque Nietzsche acredita que é preciso tomar certa distância para analisar seu tempo, se desprender de sua cultura, estar fora da submissão dos valores de sua época. Entretanto, o foco das extemporâneas não visa mais o questionamento cultural e histórico como foi visto em o Nascimento da tragédia, em que a cultura grega era utilizada para interrogar a cultura moderna. Concordamos com Denat que nas Considerações extemporâneas as questões se concentram no momento da cultura em que Nietzsche está vivendo ( $C f$. Céline Denat, 2010). 
Strauss também confunde desviando o olhar da existência e evitando o problema da dor e do sofrimento. Em meio à crítica, Nietzsche aponta que a linguagem e a escrita se prestam para representar o mundo e não para alcançar sua essência. Na visão nietzschiana, a cultura seria a unidade de estilo artístico de um povo. "O sucesso literário da obra de David Strauss junto ao público dito 'cultivado’ é percebido como sintoma duma perigosa autoinsatisfação do homem moderno frente a uma cultura que não é ainda una" 46. Por isso, Strauss seria a expressão máxima do filisteísmo. Constituíram-se os filisteus da cultura, na avaliação de Nietzsche, ao acreditarem que a sua formação é a expressão da verdadeira cultura alemã. A erudição enciclopédica e o amontoado de saberes não são cultura. Os filisteus são o contrário do artista, o avesso do que era o predileto das musas. Eles estão convictos de que sua cultura é a expressão plena e autêntica da civilização alemã, distorcendo as coisas, entendendo por civilização a sua negação. Nesse sentido, Strauss é o típico filisteu, pois está satisfeito com a erudição alemã. Nietzsche é explícito em sua perspectiva sobre Strauss, apontando seu livro como absurdo e medíocre. Descreve Strauss como um verme destruidor, já que a religião trazida por ele não passa de um paraíso para roedores (HL/ Co. Ext. I, 6, KSA 1.188) ${ }^{47}$.

$\mathrm{O}$ autor da Primeira consideração extemporânea escreve sobre a falta de caráter, sabedoria e maturidade intelectual de Strauss. Há o questionamento sobre a qualidade de sua obra como escritor; para Nietzsche ele não passa de um hipnotizador que astutamente seduz os leitores. Em vários momentos ele veste a máscara do gênio. Nietzsche aponta erros, utiliza citações do livro A antiga e a nova fé para comprovar sua deficiência e violência contra a escrita alemã, mostrando a dificuldade no entendimento das formulações mal escritas. Nietzsche escreve que o alemão de Strauss é confuso e

46 Céline Denat, 2010. p. 93.

47 Cf. F. Nietzsche, Friedrich, 2011, p. 661.

$178 \mid$ Cad. Nietzsche, Guarulhos/Porto Seguro, v.40, n.1, p. 160-192, janeiro/abril, 2019. 
ilógico. Ele termina a consideração utilizando a obra de Strauss para mostrar inúmeros exemplos do problema da língua alemã. A crítica à linguagem é o que vemos na citação de Tobias Barreto, que parece ser a única coisa que ele acata de todo o texto nietzschiano e utiliza para se defender; entretanto, ignora todo o problema da cultura e as críticas que Nietzsche fazia aos alemães.

Creio que terão compreendido bem em que medida estimo o escritor Strauss: eu o considero um ator que faz o papel do gênio ingênuo e clássico. [...] Eu queria que o escritor Strauss fosse mais sincero, assim escreveria melhor e seria menos famoso. E - se em qualquer caso quer ser um ator - então preferiria que fosse um bom ator e imitasse melhor o gênio ingênuo e o clássico, escrevendo como um clássico e como um gênio. Quer dizer que Strauss é um mau ator e um escritor infame (HL/Co. Ext. I, 10, KSA 1.216 ${ }^{48}$.

O tema principal do escrito nietzschiano de 1874 é a pseudocultura alemã que, convencida da originalidade de suas instituições pedagógicas e universitárias, recomenda ao estrangeiro, sem a menor sombra de dúvida, que é graças a ela que o povo alemão se tornou o mais culto e instruído, como se fosse um compêndio da arte, literatura e filosofia. Nietzsche relata que é muito difícil ser um bom escritor na Alemanha, pois falta terreno natural e há a carência de uma unidade de estilo. $O$ erro da opinião pública e dos formadores de opinião é acreditar que a cultura alemã também teria sua parte na vitória da guerra Franco-Prussiana (1870). O filósofo que escreveu as Considerações extemporâneas esperava que a parte mais culta e pensadora, a parte mais instruída dos alemães, percebesse o abuso do sucesso. A ideia de civilização foi perdida na Alemanha; civilização deve ser entendida como a unidade do estilo artístico através das manifestações da vida de um povo. Desse modo, Nietzsche se questiona como um alemão tão instruído como Strauss não percebeu seu estado de cultura, acumulando em torno de si todos os estilos e seguindo indiferente com a civilização.

48 F. Nietzsche, 2011, p. 681. 
Pantuzzi, T. L.

Um dos momentos polêmicos e que nos chama atenção na Primeira consideração extemporânea é a afirmação de Nietzsche que, independente do valor da cultura, os franceses possuem uma civilização autêntica, ao contrário da Alemanha, onde não existe uma civilização original. Essa afirmação é polêmica porque, além de ser algo muito controverso na época em que foi escrito, vai no caminho contrário do que Tobias Barreto e Silvio Romero acreditavam quando colocavam a Alemanha como exemplo a ser seguido. Supondo que Barreto tenha tido contato direto com o escrito de Nietzsche, talvez ele não tenha se afeiçoado tanto a Nietzsche na Primeira consideração extemporânea, porque ele critica a cultura alemã que o sergipano idolatrava, dizendo ainda que ela é tributária da cultura francesa; o texto de Nietzsche também vai contra a ideia de Romero, de que a Alemanha forneceria a configuração ideal para a salvação do povo brasileiro. Além disso, o escrito alemão desarticularia todo o plano que se tinha na escola nordestina, principalmente se for colocado diante da disputa entre as escolas no Brasil; o impacto da Primeira consideração extemporânea poderia ser fatal para o projeto de Barreto se estivesse nas mãos dos organizadores das instituições brasileiras inspiradas na cultura francesa. Nietzsche escreveu que a vitória na guerra Franco-Prussiana não dependeu da cultura alemã, mas apenas da falta de unidade e disciplina militar das tropas francesas. Interessante notar que, ao mesmo tempo em que os sergipanos procuravam se distanciar da cultura europeia e criar sua unidade, falhavam ao se filiar a uma cultura considerada decadente por Nietzsche. Por isso Tobias Barreto pode ter ignorado a parte filosófica do texto nietzschiano que versa sobre a cultura. No caso de ter lido o texto, a posição do sergipano era oposta à do filósofo alemão, como se pode ver nas citações de Romero; eles aliavam-se aos alemães e criticavam os franceses. O texto de Nietzsche seria um golpe contra a luta da "escola teuto-sergipana" que disputava seu lugar entre as instituições francesas e portuguesas do Império.

$180 \mid$ Cad. Nietzsche, Guarulhos/Porto Seguro, v.40, n.1, p. 160-192, janeiro/abril, 2019. 
Fora o escrito em que se encontra uma referência explícita de Nietzsche, há um texto de Tobias Barreto em que suspeitamos de algo referente ao filósofo alemão. Em um texto de maio de 1874, há uma citação que pode indicar uma leitura indireta de Nietzsche feita pelo germanista. $\mathrm{O}$ trecho usado como uma possível citação indireta também está ligado a Strauss. Pode-se perceber que tal citação possui termos comuns aos leitores de Nietzsche, ao mesmo tempo em que sofre de uma origem problemática e ainda desconhecida. $\mathrm{O}$ documento em questão se encontra no compilado das Obras completas de Tobias Barreto, no volume nomeado Estudos Alemães. Mesmo que não se possa comprovar uma relação direta com o pensador de Assim falava Zaratustra em 1874, o trecho e o texto são importantes para perceber se houve ou não uma mudança na relação de Barreto com Strauss. Ou seja, entre 1874 e 1876 o teólogo e exegeta alemão continuou sendo visto com os mesmos olhos? A Primeira consideração extemporânea mudou alguma coisa na concepção do pensador sergipano.

O texto Sobre David Strauss, um fragmento biográfico, traz resumidamente o percurso de Strauss como célebre teólogo e escritor alemão, comparado a outros sábios como Hegel, Schelling, Auerbach, Menzel e Wischer. A pequena biografia produzida pelo professor de Recife relata informações como a formação de Strauss e sua publicação da obra Vida de Jesus. Além das diversas informações biográficas, Barreto escreve sobre o risco que a religião corria diante de tal homem e as dificuldades que Strauss encontrava diante do sacerdócio. Fica clara a profunda admiração que o biógrafo nutre por Strauss em 1874, e isso fica ainda mais explícito ao afirmar que um dia seu nome será a assinatura do século XIX.

Strauss é para mim o tipo mais acabado daquele esforço e heroísmo intelectual, que não admite equívocos nem circunspecções interessadas, e que, por isso, tão preciso se faz ao nosso século, encarregado pela Providência de apagar os últimos vestígios da idade média. De feito, se entre os vastos espíritos do tempo, dificilmente pode-se encontrar um talento 
superior, não é nos difícil achar uma igual coragem. É certo, que antes dele, tinha Feuerbach dado exemplo de soberana ousadia, no modo de resolver as mais terríveis questões que possam agarrar-se ao cérebro humano ${ }^{\mathbf{4 9}}$.

Barreto acredita na distinção psicológica entre o sul e o norte da Alemanha; Strauss teria as características do sul alemão: "Há no interior psíquico do sul, mais singeleza, mais sentimento, mais abandono e serenidade, do que se faz aperceber nos homens do norte"50. Embora essa informação pareça ter pouca relevância, talvez seja importante para perceber a aplicação que Tobias Barreto poderia ter tido com o filósofo da Primeira consideração extemporânea em relação a escritores do norte da Alemanha, pois Nietzsche não fazia parte do conjunto de figuras célebres do sul como Kant e Hegel. Barreto claramente mostra que existe uma preferência pelos filósofos do sul, deixando transparecer que talvez não tivesse tanto apego à leitura de escritores do norte alemão.

Há um momento de ruptura na biografia sobre Strauss, em que Barreto cita Feuerbach; é nesse ponto que encontramos o vestígio do que pode ser uma leitura indireta. Ao falar dos méritos de Feuerbach, como um dos mais livres pensadores do século XIX, Barreto o menciona como o responsável pela abertura do caminho para Strauss lançar sua obra. Nesse momento, o biógrafo brasileiro escreve sobre o entusiasmo provocado pelos escritos de Feuerbach e traz o termo dionisíaco, palavra muito conhecida do vocabulário nietzschiano à época.

Bem sabemos quão grande entusiasmo provocaram os escritos do celebre filósofo, quando apareceram pela primeira vez. Houve uma espécie de embriaguez dionisíaca, segundo exprime-se Jung, por ver-se de novo unidas, como outrora entre os helenos, a poesia e a filosofia no mais estreito abraço de intimidade fraterna ${ }^{51}$.

49 Tobias Barreto, 1926. p. 487.

50 Tobias Barreto, 1926. p. 486.

51 Tobias Barreto, 1926. p. 488.

182 | Cad. Nietzsche, Guarulhos/Porto Seguro, v.40, n.1, p. 160-192, janeiro/abril, 2019. 
A embriaguez dionisíaca trazida na citação nos leva à obra Nascimento da tragédia, em que Nietzsche explora a tragédia através de duas forças artísticas distintas, a apolínea e a dionisíaca. O trágico seria resultante da relação desses dois princípios artísticos. A embriaguez é uma das características de Dioniso; Nietzsche escreve que os festivais dionisíacos eram marcados pela música, dança, êxtase e sensualidade. $O$ deus da embriaguez não limita os instintos e paixões, mas os liberta, deixando-os falar por si mesmos. Nesse sentido, o texto de Feuerbach teria um aspecto libertador para Strauss, pois libertou o teólogo de seus grilhões para que pudesse compor sua obra. Certamente, Tobias Barreto faz um elogio a Strauss nessa referência e inclusive usa os termos conhecidos pelos leitores de Nietzsche para mostrar a grandeza do autor. Se considerarmos que Tobias Barreto dominava esses conceitos a ponto de se valer deles para elogiar Strauss, por que ele não os utilizou quando falou diretamente a Nietzsche ou na Primeira consideração extemporânea? Barreto parece concordar somente com a crítica de Nietzsche sobre a língua alemã para não expor Strauss como filisteu da cultura, corroborando a ideia de uma leitura de apropriação que faz do filósofo alemão mais um literato do que um filósofo. Mais uma vez, essa apropriação parcial do texto de Nietzsche está em defesa dos interesses da instituição pernambucana ${ }^{52}$.

52 Na citação de Tobias Barreto, após o autor citar a "embriaguez dionisíaca", ele traz sua relação com Jung e é nesse ponto que temos também um enigma no texto. Todos conhecemos o famoso pupilo de Freud, Carl Gustav Jung, fundador da psicologia analítica. De fato, o famoso Jung leu Nietzsche, as obras do filósofo de Sils Maria foram responsáveis pelo desenvolvimento da psicologia junguiana (Cf. Paul Bishop, 1995. p. 1.), mas isso pode ser observado somente a partir de 1911-12, no trabalho sobre a libido. Nele Jung passa a utilizar o fenômeno do dionisíaco em suas discussões sobre a sexualidade. Para Carl Jung, o problema do Dioniso está intimamente ligado à questão da morte de Deus, e ele tenta encontrar uma solução psicológica para a crise contemporânea da religião. A solução seria a construção de um Dioniso que, através da dialética do consciente e o inconsciente, permitiria o Ego morrer e renascer de novo (Cf. Paul Bishop, 1995. p. 17.). Entretanto, a citação em que encontramos a embriaguez dionisíaca é interessante por alguns motivos. Primeiramente, C. G. Jung, o intelectual que fundou a escola de psicologia e formou centenas de terapeutas, cita o dionisíaco nietzschiano somente a partir de 1911 e nossa citação parte de 1874, ano de nascimento de Jung. Tobias Barreto falece em 1889, quando Jung tinha somente quinze anos. Portanto, podemos 
Nesse sentido, a questão que se põe é: por que o fundador da Escola do Recife não levou em conta as ideias de Nietzsche? As relações de estilo são colocadas em primeiro plano, mas não as ideias expressas na Primeira consideração extemporânea, em que estilo e cultura estão intimamente ligados. $\mathrm{O}$ estilo é muito importante para o filósofo, é a maneira pela qual ele dá vivência à escrita, sua escrita torna pensamento e vida indissolúveis. Todavia, é nele que Barreto centra sua abordagem do pensador alemão. Para Nietzsche, a cultura é algo essencial e isto está claro no texto citado pelo professor sergipano. O problema da cultura e da formação do homem persegue Nietzsche desde o Nascimento da tragédia; a superioridade da cultura grega deu aos helenos a superação do pavor da existência, através da tragédia ática em que Apolo e Dionísio selam uma união. O estranho é que Tobias Barreto não faz qualquer alusão a esses conteúdos, mostrando em sua abordagem uma apropriação com interesses bem restritos e específicos ao invés de um estudo conceitual.

Retomando o sentido do dionisíaco para Nietzsche, ele não é só um artista que projeta sua arte, mas se torna a arte mesma, não separando sua arte de si e de seus impulsos. "O homem não é mais artista, tornou-se obra de arte: a força artística de toda a natureza, para a deliciosa satisfação do Uno-primordial" (GT/NT 1, KSA $1.25)^{53}$. Toda essa relação entre Nietzsche e sua obra, $O$ nascimento da tragédia, faz total sentido com a citação da biografia escrita por Tobias Barreto. Nela encontramos a embriaguez, o dionisíaco, a união entre os gregos e a arte, e a poesia e a filosofia entrelaçadas em uma intimidade fraterna. Em $O$ nascimento da tragédia, Nietzsche acreditava que os gregos ofereciam o melhor modelo de homem, um modelo de cultura superior. O pensador alemão queria utilizar a

\footnotetext{
descartar que isso seja um erro da gráfica na data de publicação das obras completas de Barreto e, obviamente, não é o mesmo Jung famoso no campo da psicologia. Nesse sentido, temos um Jung ligado a Tobias Barreto que provavelmente tenha lido Nietzsche antes dele, ou até mesmo seja o responsável por entregar os textos do filósofo alemão para Barreto.
}

53 F. Nietzsche, Friedrich, 2007. p. 28.

184| Cad. Nietzsche, Guarulhos/Porto Seguro, v.40, n.1, p. 160-192, janeiro/abril, 2019. 
Grécia para repensar a modernidade. Afinal, por que os gregos, os mais belos tipos da humanidade, necessitaram da arte? Através dela, encararam a terrível verdade sobre a existência. A arte é uma resposta ao problema da dor, do sofrimento e da morte; os gregos usaram a epopeia para superar aquilo que mais temiam. Pela arte fugiam do terror da morte e mantinham-se vivos na memória dos homens.

Outro ponto que nos chama atenção é um dos capítulos do livro em que Sílvio Romero enaltece e defende o pensamento de Tobias Barreto, dizendo explicitamente que ambos não devem nada a Nietzsche quando concluíram e publicaram que a metafísica estava morta. Na obra Zéverissimações ineptas da crítica há inúmeras críticas que ele faz a José Veríssimo, sendo que no capítulo VI Nietzsche é mencionado inúmeras vezes. Essa afirmação sobre a metafísica não pode ser descartada porque, segundo Paim, ela constitui o evento de maior relevância no processo da Escola de Recife.

A afirmativa de Sílvio Romero de que a metafísica estava morta constitui evento da maior relevância no processo de formação da Escola de Recife. Tobias Barreto, desde logo, segundo se indicará mais pormenorizadamente logo adiante, apresenta a questão em forma de pergunta - Deve a metafísica ser considerada morta? - e a responde negativamente. Mas suas razões serão bem diversas daquelas de seus velhos mestres, motivo porque teria oportunidade de dizer que a afirmativa de Sílvio Romero "causara no corpo docente espanto igual ao que teria produzido um tiro de revólver que o moço acadêmico tivesse disparado sobre os doutores" ${ }^{54}$.

Numa parte de sua defesa, Romero afirma que quando sua tese foi escrita, Nietzsche ainda não tinha chegado a Pernambuco e é isso que chama nossa atenção. Romero escreve: "Quando a davam aqui por morta (errado!), já Frederico Nietzsche afrontava (está errado, só mais tarde Nietzsche entrou a philosophar) com as suas ousadias

54 Antonio Paim, 1981. p 19.

Cad. Nietzsche, Guarulhos/Porto Seguro, v.40, n.1, p. 160-192, janeiro/abril, 2019. 
o pensamento geral e as concepções positivas"55. Essa passagem é muito importante porque considera que em um primeiro momento Nietzsche não era tido como um filósofo, talvez apenas um literato, e só depois se pôs a filosofar, além da passagem também asseverar que a tese da morte da metafísica apareceu primeiro em Recife. Isso se manifesta mais vezes no capítulo e de forma agressiva. " $\mathrm{E}$ desgraçada estaria a metaphysica para todo sempre, se ella tivesse de esperar por Nietzsche para reflorecer ${ }^{56 "}$. E ainda aponta José Veríssimo como um pateta.

Cae na patetice, de appellar para Nietzsche como sendo um fogoso metaphysico, exatamente no tempo em que eu déra, no Recife (1875), por morta a metaphysica, n'essa defesa de theses que me valeu um processo criminal, quando a verdade, atestada por todos os biographos do autor de La Gaya Scienza, é que só mais tarde começou ele a occupar-se seriamente da philosophia ${ }^{57}$.

O trecho de Romero nos mostra, além da defesa óbvia de seu pensamento, que ele tinha o conhecimento da obra $A$ Gaia Ciência, e pode ter tido contato apenas com a versão italiana pela forma como vemos na obra. Esse dado desvia um pouco da visão e defesa dos acadêmicos de Recife que liam as obras no original e defendiam a língua germânica. Também não podemos deixar de notar que ele se baseia nos biógrafos do autor, o que nos leva a questionar se essa leitura não foi somente uma leitura de segunda mão, um comentário de algum italiano que passou a tratar Nietzsche como filósofo somente após "La Gaya Scienza". Além disso, no capítulo seguinte, Romero escreve sobre a defesa de teses e aponta que somente Tobias Barreto mostrou o sentido em que se pode considerar viva a metafísica.

55 Sílvio Romero, 1909. p. 77.

56 Sílvio Romero, 1909. p. 79.

57 Sílvio Romero, 1909. p. 78.

186 | Cad. Nietzsche, Guarulhos/Porto Seguro, v.40, n.1, p. 160-192, janeiro/abril, 2019. 
Não precisou esperar por Fred. Nietzsche. Não é só: na Philosophia no Brasil, escripta em 1876, um anno após a defesa de theses, e publicada em 1878, já eu entrei em lucta contra o exclusivismo positivista, pugnando pelo naturalismo crítico, ou evolucionismo agnostico do neokantismo ${ }^{58}$.

O problema que encontramos no texto de Romero, que ataca Nietzsche incisivamente, defendendo a todo custo seu mérito de ter dado um fim na metafísica está no tempo em que o texto é escrito. Além do tempo do escrito, também temos outra citação que nos deixa ainda mais desconfiados. Como Romero pode dizer que não precisou esperar por Nietzsche, se o filósofo alemão foi citado pelo seu companheiro Barreto no mesmo ano em que começaram a escrever juntos a obra Philosophia no Brasil? Além disso, Romero fala que tudo que fizeram foi escrito antes da chegada de Nietzsche, que a fama do filósofo alemão no Brasil é coisa recente, coisa de doze anos apenas. Isso não faz o menor sentido porque o texto que estamos citando de Romero foi publicado em 1909, ou seja, de acordo com o autor de Philosophia no Brasil, Nietzsche ficaria conhecido a partir de 1897, mas ele é citado explicitamente trinta e três anos antes por Barreto em 1876. "O livro foi escrito em 1876, só tendo sido editado dois anos depois pela tipografia Deutsche Zeitung (Porto Alegre), de Carlos von Koseritz, a quem é dedicado"59. Outro problema cronológico está na declaração de Gilberto Amado, que escreve em sua obra Minha formação no Recife que a biblioteca da Faculdade de Direito de Pernambuco recebeu Nietzsche em 1906.

Tudo isto foi pensado, escripto e publicado bem antes de se começar a falar em Nietzsche no Brasil, onde sua fama é cousa recentíssima de uns dez ou doze annos apenas a esta parte. Nem o nosso zéverissimador da crítica está em condições de dizer cousa que valha acerca do autor de Cousas Humanas ${ }^{\mathbf{6 0}}$.

58 Sílvio Romero, 1909. p. 98.

59 Antonio Paim, 1981. p 21.

60 Sílvio Romero, 1909. p. 96. 
Pantuzzi, T. L.

Cousas Humanas é a forma como o autor traduz a obra Humano, demasiado humano, de 1878. No decorrer do capítulo, Romero vai escrever mais sobre Nietzsche e mostrar seu conhecimento: "Nietzsche não se preocupou com o problema universal. Seu interesse foi sempre mais pelo problema humano, pelo destino d'esse parasita da terra, na phrase de d'Assier. ${ }^{61 "}$. É notável como o autor é tão seguro de seus estudos, pois ele ainda citará o super-homem e o niilismo e deixará claro que conhecia Assim falava Zaratustra.

Como pudemos observar, Tobias Barreto não pode ser considerado um leitor rasteiro; ele é o gênio do Recife, o professor versado em filosofia que está habituado a interpretar e analisar textos para a edição de suas críticas. Além disso, levando em conta que ele leu o texto original nietzschiano antes de citá-lo em 1876, o fundador da Escola do Recife não esteve em contato com um texto fragmentado escrito através de poemas ou aforismos. As Considerações extemporâneas são textos que procuram elucidar problemas e são diretos no que buscam tratar. Mas, apesar dessas características, Barreto não faz uma leitura propriamente filosófica, entendida como uma interpretação conceitual. Nesse sentido, percebe-se que parece ter sido feita somente a utilização da parte que lhe era conveniente do texto nietzschiano. A ausência de levantamento das questões sobre a crítica da cultura alemã nesse texto ou em qualquer outro pode ter sido feita tendo em vista a defesa da Escola de Recife. $\mathrm{O}$ texto de Sílvio Romero mostra com muita ênfase a aflição de não ser reconhecido pela sua tese e a ânsia de salientar que Nietzsche não teve importância naquele momento.

Se levarmos em conta o entrecruzamento filosófico e histórico da época, colocando os relatos dos historiadores, membros da Escola de Recife, as divergências encontradas nas datas de publicações, a competição entre as instituições de ensino e a importância dada por Romero ao trabalho de Nietzsche em defesa de sua tese, podemos

61 Sílvio Romero, 1909. p. 96.

188 | Cad. Nietzsche, Guarulhos/Porto Seguro, v.40, n.1, p. 160-192, janeiro/abril, 2019. 
levantar essa hipótese de que Nietzsche está de alguma forma ligado aos interesses da Escola de Recife, já que a presença de seus escritos e de discussões sobre suas ideias na Faculdade de Direito de Pernambuco é indiscutível. O escrito do filósofo alemão e as menções trazidas por Barreto e Romero foram importantes para a introdução das obras do autor da Primeira consideração extemporânea adentrar a faculdade pernambucana e lá ganhar espaço entre os alunos vindouros que tiveram contato com as obras completas e na língua original. Nota-se que a parte da filosofia nietzschiana desprezada pelo fundador da Escola de Recife pode ter sido tomada em defesa dos interesses da instituição, pois ia contra o projeto tedesco de Tobias Barreto e Sílvio Romero, que colocavam a cultura alemã acima da francesa. Além disso, pode-se perceber que a leitura e as menções a outros autores, como Schopenhauer por exemplo, nas obras do professor sergipano, aparecem somente após o registro que se tem da leitura da Primeira consideração extemporânea, que pode indicar e fortalecer ainda mais o papel que Nietzsche teria nos bastidores da faculdade nordestina.

Barreto propõe uma estética como uma nova maneira de escrever e pensar, como forma de expressão criadora que se sobrepõe à de Strauss (dominante na época), como uma forma de escrita contra o dogmatismo. Expressão criadora significaria primeiramente a ruptura com os dogmatismos reinantes, seja o religioso, através do neotomismo tardio cultivado nas escolas de filosofia da época, seja o científico através do também extemporâneo culto às ideias de Comte. Nossa hipótese é de que a apropriação pontual (e parcial) de Nietzsche obedecia a esse imperativo, e que a intenção não é exatamente reformar, mas dilapidar e reconstruir, do ponto zero, a filosofia brasileira. No Brasil, devido a diversos problemas de conservação histórica, não temos acesso às obras completas que os primeiros leitores de Nietzsche possam ter lido. Muito do material com que trabalhamos está incompleto ou em fase de recuperação; quase todas as obras brasileiras dos pensadores da Escola de Recife que compôs o corpo desse artigo não estão digitalizadas. 
Por exemplo, a coleção de obras completas de Tobias Barreto tem cerca de cinco mil páginas e quase nenhuma delas está no formato digital. Nietzsche foi lido no Brasil em um momento em que quase não encontrava leitores na Alemanha nem tradutores em países vizinhos, e também durante um ciclo de insurgências regionais e de eclosão de movimentos que reivindicavam, entre outras demandas, o fim da escravidão e a proclamação da República.

\title{
Allemanism in Recife and the First Reception of Nietzsche in Brazil
}

\begin{abstract}
The purpose of this article is to investigate the first reception of Nietzsche's philosophy in Brazil, which happened at Escola de Recife (Recife's School). For this purpose, at first, by using a historical-philosophical approach, the article analyzes the formation of the intellectual movement within the Pernambuco faculty, whose goals included to build a national identity which could detach itself from the European predominance. Then, the article analyzes the first explicit quotation by Tobias Barreto in 1876, which came amid this moment of sociocultural effervescence and would become the motto for the future students, conceiving a more creative and combative philosophy. Finally, the article investigates Germanist scholar members who, besides bringing German studies to the Pernambuco faculty, also believed that these could provide Brazil with cultural enhancement through the Germanism.
\end{abstract}

Keywords: Nietzsche, reception, Recife's School, Tobias Barreto, Germanism, Brazil.

\section{Referências}

ABRÃO, Bernadette Siqueira (org.), História da filosofia: Col. "Os Pensadores", São Paulo: Editora Nova Cultural, 2004.

ASCHHEIM, Steven E. The Nietzsche legacy in Germany, 1890-1990. California: University of California press, 1992.

$190 \mid$ Cad. Nietzsche, Guarulhos/Porto Seguro, v.40, n.1, p. 160-192, janeiro/abril, 2019. 
O allemanismo em Recife e a primeira recepção de Nietzsche no Brasil

BARRETO, Tobias. Obras completas. 10 vols. Rio de Janeiro: Editora Pongetti, 1926.

Estudos de filosofia. São Paulo: Grijalbo, 1977

Estudos Alemães. Rio de Janeiro: Record, 1991.

BARRETO, Luiz Antonio. Tobias Barreto: uma bibliografia. In: BARRETO, Tobias. Crítica de literatura e arte. Rio de Janeiro: Record, 1990.

BISHOP, Paul. The Dyonysian Self: C. G. Jung's reception of Friedrich Nietzsche. New York: de Gruyter, 1995

CANDIDO, Antonio. Sílvio Romero: teoria, crítica e história literária. Rio de Janeiro: Livros Técnicos e Científicos, São Paulo: Edusp, 1978.

CHIARETTO, Marcelo. O nativismo crítico e germanista de Sílvio Romero. In: $O$ eixo e a roda: revista de literatura brasileira, Minas Gerais, v. 21, n. 2, p. 145-160, 2012.

FAUSTO, Boris. História do Brasil. São Paulo: Editora da Universidade de São Paulo, 2013.

DENAT, Céline. A filosofia e o valor da história em Nietzsche. Uma apresentação das Considerações extemporâneas. In: Cadernos Nietzsche, São Paulo, no. 26, p. 86-96, 2010.

KRUMMEL, Richard Frank. Nietzsche und der Deutsche Geist, Band I. Nova Iorque: de Gruyter, 1998.

MARTON, Scarlett. Extravagâncias: Ensaios sobre a filosofia de Nietzsche. São Paulo: Discurso editorial, 2001.

MARTINS, Wilson. História da Inteligência Brasileira (1897 - 1914), v. 5. São Paulo: T. A. Queiroz, 1996.

NIETZSCHE, Friedrich W. Sämtliche Werke. Kritische Studienausgabe (KSA). 15 vols. Organizada por Giorgio Colli e Mazzino Montinari. Berlin: de Gruyter \& CO., 1988.

Obras completas: Volumen I Escritos de juventud. Madrid: Tecnos, 2011.

Obras incompletas (Coleção Os Pensadores). Tradução de Rubens Rodrigues Torres Filho. São Paulo: Editora Nova Cultural, 2000. 
Pantuzzi, T. L.

Nascimento da tragédia. Tradução de J. Guinsburg. São Paulo: Companhia das Letras, 2007.

PAIM, Antonio. A filosofia da Escola do Recife. São Paulo: Editora Convívio, 1981.

ROMERO, Sílvio. A philosophia no Brasil - Ensaio crítico. Porto Alegre: Typographia da deutsche zeitung, 1878.

.Zéverissimações ineptas da crítica: repulsas e desabafos. Porto, Oficinas do Comercio do Porto, 1909.

. Considerações indispensáveis de Sylvio Roméro. In: BARRETO, Tobias. Obras completas. Vol. 6. Rio de Janeiro: Editora Pongetti, 1926.

SCHOBER, Angelika. Nietzsche et la France. Cent ans de réception française de Nietzsche. Thése de doctorat d'État, 3 vols.. Université de Paris X: Nanterre, 1990.

SMITH, Douglas. Transvaluations: Nietzsche in France 1872-1972. Nova York: Oxford University Press Inc, 1996.

SOBEJANO, Gonzalo. Nietzsche en España. Madrid: Editorial Gredos, 1967.

STEFANI, Manuela Angela. Nietzsche in Italia. Rassegna Bibliografica, 18931970. Assisi, Roma, 1975.

Artigo recebido para publicação em 10/01/2019

Artigo aceito para publicação em 31/01/2019

192 | Cad. Nietzsche, Guarulhos/Porto Seguro, v.40, n.1, p. 160-192, janeiro/abril, 2019. 